\title{
Developmental Differences in Neurohumoral Modulation of the Cat Lower Esophageal Sphincter
}

\author{
CRAIG HILLEMEIER AND PIERO BIANCANI \\ C. S. Mott Children's Hospital, University of Michigan, Ann Arbor, Michigan 48109 [C.H.]; and The Department \\ of Pediatrics and Internal Medicine, Brown University, Rhode Island Hospital, Providence, \\ Rhode Island 02902 [P.B.]
}

\begin{abstract}
It is possible that age-related differences in gastroesophageal function during infancy may predispose the infant to abnormalities. We have therefore evaluated developmental differences in neurohumoral modulation of lower esophageal sphincter function in the cat. These studies were performed in an in vitro setting. In the adult cat, lower esophageal sphincter smooth muscle and postganglionic inhibitory neurons are more sensitive to muscarinic agonists than in the kitten. The circular smooth muscle of the adult lower esophageal sphincter is also more responsive to neurally mediated relaxation, brought about by electrical stimulation. However, there is no difference in response to exogenous vasoactive intestinal peptide between the two age groups. These data suggest that developmental differences in neurohumoral modulation of the lower esophageal sphincter occur in the cat. (Pediatr Res 26: 39-42, 1989)
\end{abstract}

\section{Abbreviations}

GER, gastroesophageal reflux

LES, lower esophageal sphincter

TTX, tetrodotoxin

VIP, vasoactive intestinal peptide

DMPP, 1,1-Dimethyl-4-phenylpiperazinium iodidine

GER is a common occurrence during infancy, resulting in significant morbidity (1). Although it is reasonable to expect that abnormalities in LES function may be the cause of infant GER, the developmental differences responsible for this phenomenon are unclear.

The newborn infant undergoes many physiologic adaptations during development. We have recently shown that the kitten LES is unable to produce intraluminal pressure as high as the adult (2) despite being able to generate high amounts of stress in the LES circular muscle layer. This apparent contradiction is explained by the finding that the kitten LES has reduced thickness and thickness/radius ratio in the circular muscle layer, which causes a mechanical disadvantage in generating in vivo LES pressure.

Cat LES tone, in vitro, is myogenic as it is not affected by TTX although LES relaxation is neurally mediated. In vivo LES

Received February 4, 1988; accepted March 13, 1989

Correspondence A. Craig Hillemeier, M.D., Director, Pediatric Gastroenterology, Medical Science Research Building I, 1150 W. Medical Drive, Room 1510 E/ Box 0658, Ann Arbor, MI 48109.

C.H. is a recipient of NIH Grant 5R29-HD20054-02 and P.B. is a recipient of NIH Grant DK-RO 28614. tone, however, may be modulated by various neural or hormonal influences. It has been suggested that in vivo LES resting pressure has a cholinergic component in man (3) and an $\alpha$-adrenergic component of resting tone has been demonstrated (4) in the in vivo cat LES.

Studies of receptor activity in the LES during the newborn period would be of interest as GER is common during this period and decreases in frequency towards the end of the first year of life. Little attention, however, has been paid to modulation of LES activity during the newborn period. In vitro studies in the opossum (5) and in vivo studies in the beagle pup (6) suggest that the infant LES responds less than the adult to exogenous gastrin.

The possibility that developmental differences in modulation of LES function may predispose the newborn LES to incompetence leads to the present investigation in which we propose to examine the development of neurohumoral modulation of LES pressure.

\section{MATERIALS AND METHODS}

Our study was performed on 6-wk-old recently weaned kittens and adult cats $3-5 \mathrm{~kg}$ in wt. After midline laparotomy, the LES was identified, and a suture was placed on the outer surface of the esophagus at the location of the high pressure zone as described previously (7).

Stomach, LES, and esophagus were removed in toto and pinned on a wax block maintaining their in vivo orientation and dimensions. A metal block with razor blades $1.75-\mathrm{mm}$ apart was used to cut rings from the LES region. Mucosa and muscularis mucosa were removed by sharp dissection under microscope. LES rings containing circular muscle bundles were mounted in individual muscle chambers between platinum wire hooks. The lower hook was rigidly attached to the bottom of the muscle chamber and the upper hook was attached to a force transducer (UC2 Statham-Gould Instruments) mounted on a micrometer stage (Edmunds Scientific Company, Barrington, NJ).

The tissue was perfused with oxygenated Tyrode's solution maintained at constant $37^{\circ} \mathrm{C}$ temperature. After mounting, the rings were allowed to equilibrate for $30 \mathrm{~min}$ before the initial stretch was applied. Stretch was obtained by vertical movement of the micrometer stage holding the force transducer. The rings were electrically stimulated by electrodes placed longitudinally on either side of the muscle chamber.

When pharmacologic substances were used, perfusion was stopped and a fixed amount of solution was kept in the chamber. Stopping the perfusion caused no temperature change and did not affect the viability of tissues or reproducibility of results over a period of several hours.

Statistical analysis was performed using an unpaired Student's $t$ test. 
Experimental protocol. After the rings were mounted in the bath, they were stretched to near the point of optimal tension development as has previously been determined $(1,7)$. The rings from the LES soon developed and maintained tonus. After the initial stretch, the strips were allowed to equilibrate at their resting tone for $1 \mathrm{~h}$ while being perfused continuously with oxygenated Tyrode's solution. The Tyrode's solution contained $137 \mathrm{mM}$ $\mathrm{NaCl} ; 12 \mathrm{mM} \mathrm{NaHCO} ; 1.8 \mathrm{mM} \mathrm{NaH} \mathrm{PO}_{4} ; 2.7 \mathrm{mM} \mathrm{KCl} ; 2.7$ $\mathrm{mM} \mathrm{CaCl}_{2} ; 5.5 \mathrm{mM}$ glucose; and $1.0 \mathrm{mM} \mathrm{MgCl}$. The perfusate was maintained at $37^{\circ} \mathrm{C}$ and equilibrated with a gas mixture that contained $95 \% \mathrm{O}_{2}$ and $5 \% \mathrm{CO}_{2}$. During the equilibration period tension developed. In the LES strips tension remained steady or increased, although it decreased in the gastric and esophageal strips.

Before the instillation of each drug in the muscle bath, the perfusion was stopped for a period of $20 \mathrm{~min}$. After this equilibration in Tyrode solution, force developed by the rings was recorded (basal force), and the drug to be studied was added to the bath. Drugs were given cumulatively at 3-min intervals to obtain dose response relationships. The drugs used in this experiment were bethanechol (Merck Sharp and Dome), atropine (Lilly), nicotine sulfate, DMPP (Pfaltz \& Bauer, Inc. Stamford, CT), TTX (Calbiochem-Behring, La Jolla, CA), phenylephrine (Sigma Chemical Co., St. Louis, MO), epinephrine (Parke Davis), and vasoactive intestinal peptide (Bachem). Electrical stimulation was performed with 6-s trains and at frequencies of 1 to 10 $\mathrm{Hz}$ and pulse durations that ranged from 0.2 to $1 \mathrm{~ms}$.

Passive force was obtained at the end of the experiment by incubating the specimens in $5 \mathrm{mM}$ EDTA which chelates extracellular calcium and, within 20-30 min, causes a complete loss of tonus leaving only passive forces. The relaxation caused by electrical stimulation or pharmacologic agent could therefore be expressed as a percent of the total relaxation achieved when the muscle tone is totally removed (i.e. the passive state). Percent relaxation was therefore expressed as: $100 \times$ (basal force - force during relaxation)/(basal force - passive force). Contraction is expressed as the percent of maximal contraction, obtained at the end of the experiment with $10^{-4} \mathrm{M}$ bethanechol.

\section{RESULTS}

At all parameters tested electrical stimulation caused LES relaxation in both the kitten and the adult cat (8). The relaxation was neurally mediated, as it was inhibited by TTX, a neuropoison that eliminates axonally transmitted neural impulses. In the kitten, LES relaxation was significantly less than in the adult (Fig. 1) at pulse durations of 0.1 and $0.2 \mathrm{~ms}$ whereas at $0.5 \mathrm{~ms}$ there was no difference.

VIP is a candidate neurotransmitter responsible for LES relaxation since it relaxes the LES through direct action on myogenic receptors, is released on electrical stimulation of the LES, and VIP antiserum blocks electrically induced relaxation of the LES $(9,10)$. Kitten and adult ILES exhibit the same dose response relationships to exogenously administered VIP (Table 1) with the $\mathrm{ED}_{50}$ for the kitten in response to VIP being $3.45 \times 10^{-8}$ and the adult being $2.23 \times 10^{-8}$.

Norepinephrine is an adrenergic agonist that contracts the LES through $\alpha$-adrenergic receptors and exhibit identical dose response relationships in both the adult cat and kitten LES (Table 1) with the kitten $\mathrm{ED}_{50}$ at $2.61 \times 10^{-6}$ and the adult $3.10 \times 10^{-6}$.

Bethanechol is a muscarinic agonist which causes contraction of the LES by binding predominantly to muscarinic M2-type myogenic receptors because bethanechol dose response relationships are unchanged by TTX. The ED $\mathrm{ED}_{50}$ of the kitten LES in response to bethanechol was $9.4 \times 10^{-6} \mathrm{M}$ and that of the adult LES was $1.3 \times 10^{-6} \mathrm{M}$. The response to bethanechol was significantly greater in the adult cat at the points noted on the graph (Fig. 2). This finding suggests that a difference in myogenic muscarinic receptors exists between the kitten and the adult.

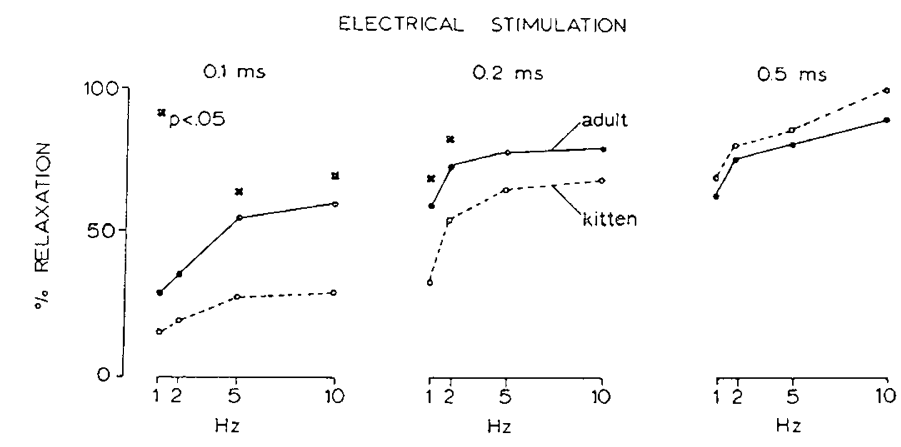

Fig. 1. Response of the LES in the 6-wk-old kitten $(n=8)$ and adult $(n=8)$ to electrical stimulation. Trains of stimulation were $6 \mathrm{~s}$ in duration. The duration of stimulation was $0.1,0.2$, and $0.5 \mathrm{~ms}$ with the frequencies between 1 and $10 \mathrm{~Hz}$.

Nicotine sulfate at low doses $\left(10^{-8}\right.$ and $\left.10^{-7}\right)$ contracted the adult LES and at higher doses caused relaxation of the LES. The contraction $\left(0.24 \pm 0.07 \mathrm{~g}\right.$ at $10^{-8} \mathrm{M}$ and $0.27 \pm 0.06 \mathrm{~g}$ at $10^{-7}$ $\mathrm{M})$ was resistant to TTX but was abolished by atropine whereas the relaxation was abolished by TTX. The direct contractile effect of nicotine on the adult cat LES smooth muscles was not seen in the kitten. Both the kitten and adult LES showed relaxation at $10^{-6} \mathrm{M}$ nicotine with the kitten relaxing to a greater degree (Fig. 3). The relaxation of the adult LES was increased by atropine but the kitten LES was not affected, suggesting both a direct contractile and postganglionic inhibitory effect in the adult at this dose and the absence of the direct contractile affect in the kitten. Still higher doses of nicotine $\left(3 \times 10^{-6}\right.$ and $\left.10^{-5} \mathrm{M}\right)$ caused greater relaxation in the adult LES $(* 65.8$ and $* 89.2 \%)$ than in the kitten LES $(32.4$ and $63.2 \%)\left({ }^{*} p<0.05\right)$. The differences in relaxation caused by high doses of nicotine were abolished by pretreatment with atropine $10^{-6}$. Atropine, therefore, reduced relaxation in the adult but had no effect on the kitten LES, suggesting muscarinic postganglionic inhibitory activity in the adult not present in the kitten.

DMPP relaxed the LES at all doses used (Fig. 4) and caused significantly $(p<0.01)$ greater relaxation in the adult at points noted in the graph. This relaxation is neurally mediated as it is blocked by TTX. In the kitten LES the $\mathrm{ED}_{50}$ was $1.04 \times 10^{-5} \mathrm{M}$ and $1.90 \times 10^{-6}$ in the adult. As with the higher doses of nicotine, this difference is abolished by pretreatment with atropine $10^{-6}$ resulting an $\mathrm{ED}_{50}$ of $9.71 \times 10^{-6}$ in the kitten and $8.4 \times 10^{-6}$ in the adult cat suggesting muscarinic postganglionic inhibitory activity in the adult which is not present in the kitten.

\section{DISCUSSION}

LES tone is largely myogenic but can be affected by a large number of substances both in vivo and in vitro. Our study demonstrates that, in vitro, receptor activity which may modulate LES tone is altered during development of the cat LES. In the kitten LES muscarinic activity is decreased both in muscle cells and neurons, although myogenic $\alpha$-adrenergic activity and response to the putative inhibitory neurotransmitter VIP remain unchanged.

Changes in neurohumoral modulation during development have been studied previously in several organ systems. Ligand binding studies have shown an increase in the number of cholinergic receptors with age in the CNS (11) vas deferens (12) and an increase of gastrin receptors on the parietal cell of the stomach during the newborn period (13). Functionally, the parietal cell does not produce acid in response to exogenous gastrin in the immediate newborn period in the rat, and shows increasing levels of responsiveness at the time of weaning, coincident with the emergence of gastrin receptors as detected by ligand binding studies $(14,15)$. 
Table 1. Percent LES relaxation

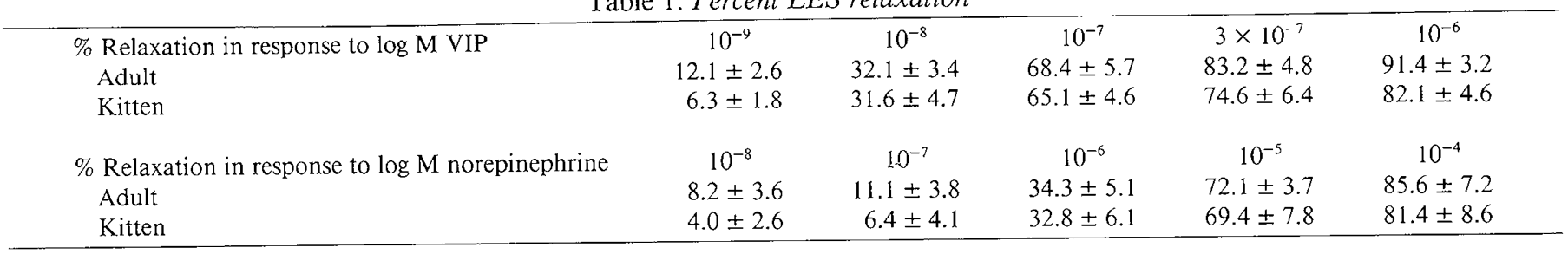

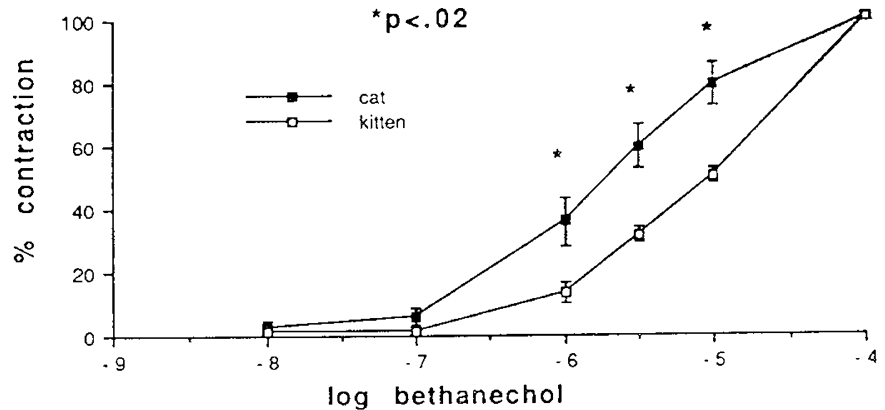

Fig. 2. The dose response to bethanechol in the LES of the adult ( $n$ $=7)$ and the kitten $(n=8)$ expressed as \pm SEM. The asterisk marks doses at which the adult response was significantly greater than the kitten $\left({ }^{*} p<0.02\right)$.

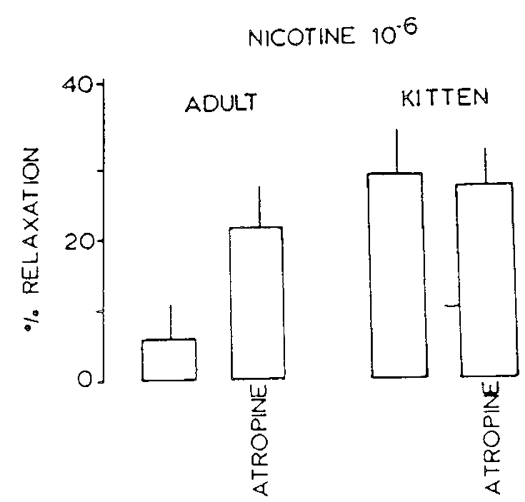

Fig. 3. At $10^{-6} \mathrm{M}$ nicotine the relaxation of the adult LES $(n=8)$ is significantly increased $(p<0.01)$ by pretreatment with atropine $\left(10^{-6}\right.$ $\mathrm{M})$ although the relaxation of the kitten LES $(n=9)$ is unaffected.

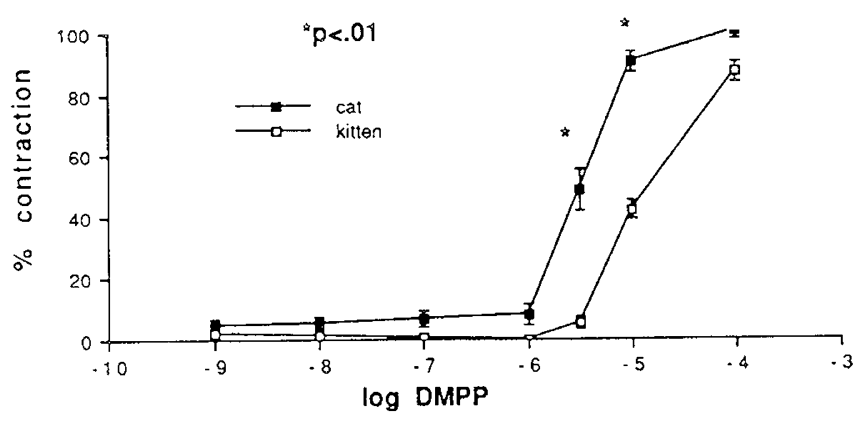

Fig. 4. The dose response to DMPP in the adult cat $(n=8)$ and the kitten $(n=7)$ expressed \pm SEM. The asterisk denoted concentrations at which the adult LES was significantly more sensitive to DMPP than the kitten.

It has recently been shown that in the LES muscarinic receptors are present on both muscle cells and neurons (16). The muscarinic receptors present in the smooth muscle cell cause contraction and have been designated as M2 receptors although those on the neurons cause release of inhibitory neurotransmitter resulting in smooth muscle relaxation, and have been designated as $\mathrm{M} 1$ receptors.

In our study the kitten LES was less responsive than the adult to stimulation with bethanechol and this difference was unchanged by TTX, suggesting decreased myogenic muscarinic activity. The decreased responsiveness to myogenic muscarinic stimulation in the kitten is further supported by differences in response to nicotine. In the adult low doses of nicotine cause contractile activity that is TTX resistant but this contractile activity is not seen in the kitten. The contractile activity in the adult is blocked by atropine and, therefore, it is myogenic, muscarinic, and M2 type. At a higher dose of nicotine $\left(10^{-6}\right)$ both the adult and kitten LES show relaxation. The fact that atropine increased the relaxation in the adult LES suggests a mixed response in the adult LES to this dose of nicotine; a direct myogenic affect which is blocked by atropine and a postganglionic inhibitory neuronal affect which is not as sensitive to atropine. The kitten LES does not have this direct contractile affect in response to nicotine, and does not have its relaxation increased by pretreatment with atropine.

Higher doses of nicotine and DMPP stimulated postganglionic inhibitory neurons, in both kitten and adult, resulting in relaxation of LES tonus, that was abolished by TTX. The difference in sensitivity between the adult and kitten LES was abolished by pretreatment of the tissue with atropine $\left(10^{-6} \mathrm{M}\right)$ suggesting that both DMPP and nicotine have a component of muscarinic stimulation on the postganglionic inhibitory neuron (either directly or through a postganglionic cholinergic neuron that stimulates the inhibitory neuron) of the adult that is not present in the kitten.

In summary, in the adult, the greater sensitivity to contraction in response to bethanechol and nicotine would suggest greater myogenic muscarinic M2 activity, whereas the enhanced inhibitory response to DMPP and higher doses of nicotine would point to greater muscarinic M1 neural activity in the postganglionic inhibitory neurons.

The kitten LES was also less sensitive to relaxation induced by electrical field stimulation than the adult LES. This relaxation is the result of stimulation of post-ganglionic neurons which release an inhibitory transmission, possibly VIP $(9,10)$. It is blocked by TTX, but not affected by ganglionic blockers. The reduced response to electrical stimulation is unlikely to be due to reduced inhibitory receptor numbers or activity because the kitten LES exhibits the same sensitivity to exogenously administered VIP as the adult. It is possible that the inhibitory neurons in the kitten LES may be less developed than in the adult resulting in a reduction of neurotransmitter released. It has been recognized that myelinization of the vagus occurs to a significant degree during the postnatal period (17), and it is therefore possible that, because of different stages of neural development and of myelinization, the kitten neurons may be less inclined to release inhibitory neurotransmitter upon electrical stimulation.

In summary, the kitten LES responds differently than the adult to agents that modulate LES tension. The kitten LES is less sensitive to myogenic and neurogenic muscarinic stimulation and to electrical field stimulation. Further investigations should 
consider that differences in modulation of LES activity may play a role in predisposing the infant to GER.

\section{REFERENCES}

1. Hillemeier AC, Grill B, McCallum R, Gryboski J 1983 Esophageal and gastric abnormalities in gastroesophageal reflux during infancy. Gastroenterology $84: 741-746$

2. Hillemeier C, Gryboski J, McCallum R, Biancani P 1985 Developmental characteristics of the lower esophageal sphincter in the kitten. Gastroenterology 89:760-766

3. Dodds WJ, Dent J, Hogan WJ 1982 The effect of atropine on esophageal motor function in man. Am J Physiol 240:G290-G296

4. Behar J, Kerstein M, Biancani P 1982 Neural control of the lower esophageal sphincter in the cat: studies on the excitatory pathways to the lower esophageal sphincter. Gastroenterology 82:680-688

5. Cohen S 1974 Developmental characteristics of lower esophageal sphincter function: a possible mechanism for infantile chalasia. Gastroenterology $67: 252-258$

6. Spedale SB, Weisbrodt NW, Morris FW 1982 Ontogenic studies of gastrointestinal function II. Pediatr Res 16:881-885

7. Biancani P, Zabinski M, Kerstein M, Behar J 1982 Lower esophageal sphincter mechanics: anatomic and physiologic relationships of the esophagastric junction of cat. Gastroenterology 82:468-475
8. Christensen J, Conklin JL, Freeman B 1973 Physiologic specialization at the esophagastric junction in three species. Am J Physiol 225:1265-1270

9. Biancani P, Walsh $\mathrm{JH}$, Behar J 1984 Vasoactive intestinal polypeptide: a neurotransmitter for lower esophageal sphincter relaxation. J Clin Invest 73:963-967

10. Goyal RK, Rattan S 1980 VIP as a possible neurotransmitter of non-cholinergic, non-adrenergic inhibitory neurons. Nature 288:378-380

11. Kuhar MJ, Birdsall NJM, Burgen ASV, Hulme EC 1980 Ontogeny of muscarinic receptors in rat brain. Brain Res 184:375-383

12. Higuchi H, Takeyasu K, Watanabe W, Uchida S, Yoshida H 1982 Developmental changes in alpha adrenergic and muscarinic receptor-mediated contractions of rat vas deferens. Japan J Pharmacol 32:671-678

13. Takeuchi W, Peitsch W, Johnson LR 1981 Mucosal receptor. V. development in newborn rats. Am J Physiol 3:G163-G169

14. Ikezaki M, Johnson LR 1983 Development of sensitivity to different secretagogues in the rat stomach. Am J Physiol 244:G165-G170

15. Garzon B, Cucroc R, Onolfo JP, Desjeux JF, Geloso JP 1982 Biphasic development of pentagastrin sensitivity in rat stomach. Am J Physiol 242:G111-G115

16. Gilbert R, Rattan S, Goyal RK 1984 Pharmacologic identification, activation and antagonism of two muscarinic receptor subtypes in the lower esophagea sphincter. J Exp Pharm Ther 230:284-291

17. Sachis PN, Armstrong DL, Becker LE, Bryan A 1982 Myelination of the human vagus nerve from 24 weeks post conceptual age to adolescence. J Neuropathol Exp Neurol 41:466-472 